\title{
Degradation Phenol Wastewater by Heating Activated Persulfate
}

\author{
Wang Bing, Wang Wei \\ School of Municipal and Environmental Engineering, Shenyang Jianzhu University, Shenyang, China \\ Email address: \\ 18202460111@163.com (Wang Bing),wangwei159815@163.com (Wang Wei)
}

\section{To cite this article:}

Wang Bing, Wang Wei. Degradation Phenol Wastewater by Heating Activated Persulfate. International Journal of Environmental Monitoring and Analysis. Vol. 7, No. 1, 2019, pp. 14-21. doi: 10.11648/j.ijema.20190701.12

Received: December 3, 2018; Accepted: April 1, 2019; Published: April 28, 2019

\begin{abstract}
In order to solve the problem of refractory industrial wastewater, the phenol wastewater was used as the treatment object. The treatment effect of heated activated potassium persulfate oxidation on phenol wastewater was studied. The reaction time, reaction temperature, $\mathrm{K}_{2} \mathrm{~S}_{2} \mathrm{O}_{8}$ dosage, $\mathrm{pH}$ and initial phenol concentration on the treatment effect were discussed respectively. and the reaction free mechanism analysis was carried out according to the test results. Under the conditions of heat activation at $35^{\circ} \mathrm{C}$, when the initial concentration of phenol is $200 \mathrm{mg} / \mathrm{L}$, the reaction time is $180 \mathrm{~min}$, the $\mathrm{pH}$ is $3, \mathrm{~m}\left(\mathrm{~K}_{2} \mathrm{~S}_{2} \mathrm{O}_{8}\right)$ : $\mathrm{m}\left(\mathrm{C}_{6} \mathrm{H}_{6} \mathrm{O}\right)=1$, the optimum removal rate of phenol was $13.61 \%$, and the optimal removal rate of COD was $12.30 \%$. When the temperature was raised to $85^{\circ} \mathrm{C}$ under the same reaction conditions, the removal rates of phenol and COD increased to $32.17 \%$ and $26.72 \%$, respectively.
\end{abstract}

Keywords: Heat Activation, Persulfate Phenol, Wastewater

\section{Introduction}

The phenol wastewater has a high concentration and is difficult to degrade, which is very harmful. Due to its "three-way" potential, phenolic compounds have long been listed by the US Environmental Protection Agency as one of the 129 priority-controlled pollutants. It is also listed as one of the dangerous wastewaters that China needs to address [11-12]. Phenol-containing wastewater is one of the harmful waste waters and has been identified as a key solution for China's water pollution control plan. The activated persulfate advanced oxidation process is used as a strong oxidizing power. The reaction speed is very fast. The operation process is very simple. In recent years, Chinese and foreign scholars have generally paid attention to new high-efficiency secondary pollution wastewater treatment methods. The method can also be used as a main link of pretreatment of refractory industrial wastewater into refractory substances. It has become a practical application example for degradable substances and improving the biodegradability of wastewater. However, if the application field and application range are to be expanded, further research on activated persulfate oxidation methods is needed.

As an important part of the Fenton reagent method, the persulfate oxidation method with $\cdot \mathrm{SO}_{4}{ }^{-}$as the main active material has gradually entered the line of sight as a fast and effective new sewage treatment method. Persulfate can be classified as $\mathrm{HO}^{\circ}$ a derivative of $\mathrm{H}_{2} \mathrm{O}_{2}$, which is very similar in structure to $\mathrm{H}_{2} \mathrm{O}_{2}$. Therefore, $\mathrm{SO}_{4}{ }^{-}$has an oxidation-reduction potential equivalent to $\mathrm{OH}$, and due to the influence of the $\mathrm{SO}_{3}$ group, the -O-O- bond length of the persulfate increases, and the bond energy decreases, and is not activated. In the case, the oxidizing ability is limited. On the other hand, $\mathrm{SO}_{4}{ }^{-}$still exerts strong oxidizing properties under acidic and neutral conditions and can cause specific oxidation of certain pollutants. Therefore, the development prospect of persulfate oxidation in the field of refractory industrial wastewater treatment should not be underestimated.

The heat activated persulfate oxidation method obtains a sufficiently large activation energy $(140.2 \mathrm{~kJ} / \mathrm{mol})$ mainly by increasing the temperature to force the double oxygen bond to break, and finally obtains sulfate [15]. Thermal activation is a deeper method of persulfate activation currently under study. It is mainly used for the treatment of groundwater and soil remediation technologies. During the research, it was found that the higher the reaction temperature, the better the heat activation effect in a certain temperature range. In addition, in the heat activation process, in addition to the temperature, it is 
necessary to comprehensively consider the concentration of persulfate. The effect of different activating factors such as $\mathrm{pH}$ and ionic strength on the degree of activation.

Liu Guoqiang et al [16] used a heat activated $\mathrm{K}_{2} \mathrm{~S}_{2} \mathrm{O}_{8}$ method to degrade 2-chlorophenol. The degradation of temperature, $\mathrm{pH}$, humic acid (HA) and inorganic ions was investigated in the experiment. The results show that increasing the concentration of $\mathrm{K}_{2} \mathrm{~S}_{2} \mathrm{O}_{8}$ or increasing the reaction temperature is beneficial to the degradation of 2-chlorophenol. The degradation process conforms to quasi-first-order reaction kinetics. The activation energy was $4.32 \mathrm{~kJ} / \mathrm{mol}$. In this heat activated system, degradation under acidic conditions is significantly better than alkaline conditions. In addition, the degradation of 2-chlorophenol is affected by humic acid, acid inhibition, Cl-inhibition is particularly obvious under acidic and neutral conditions, but alkaline conditions have little effect. 2-Chlorophenol will eventually be in small molecular organic matter. Degraded into small molecular organic substances by action. $\mathrm{SO}_{4}{ }^{-}$.

In recent years, as an advanced oxidation technology that has attracted much attention in the field of sewage treatment, the active sulfate oxidation method has obvious advantages, but at the same time there are some inconveniences. Therefore, the activation of sulfuric acid is restricted in practical applications. Although the salt oxidation method has the advantages of fast reaction, strong oxidizing property and simple operation, the reaction conditions are limited, the pollutants cannot be completely degraded, the dosage of the medicament is large, and the cost is too high, so the method cannot be widely applied in practical engineering [13-14]. Therefore, the purpose of this experiment is to explore the effects of different reaction conditions on the degradation effect and find the best conditions.

\section{Materials and Analytical Methods}

\subsection{Materials}

The test uses a standard JJ-4A six-type automatic mixer. The agitation speed and agitation time can be adjusted as needed. In the test, it is necessary to discuss the effect of temperature on the phenol treatment effect and provide constant temperature reaction conditions. Therefore, the HH-4 digital constant temperature water bath was selected as one of the main test instruments. The phenol used in the experiment was analytically pure

Table 1. Main experimental equipment and instruments.

\begin{tabular}{ll}
\hline Instrument and equipment name & model \\
\hline Digital thermostat water bath & HH-4 type \\
Ultraviolet visible spectrophotometer & T6 new century \\
Electric distilled water & Jyzd type \\
Electronic heating rod & DZ-3050 \\
Electronic analytical balance & XS1003SX \\
\hline
\end{tabular}

\subsection{Analytical Methods}

The water quality indicators of phenol wastewater in the test are mainly the removal rates of phenol and COD. Therefore, it is necessary to determine the phenol concentration and COD to measure the degradation effect of phenol wastewater. The test method used in the test is appropriately selected in accordance with the provisions of the "Water and Wastewater Monitoring and Analysis Method (Fourth Edition).

\subsubsection{Determination of Phenol Mass Concentration}

The mass concentration of phenol was determined by 4-aminoantipyrine (4-AAP) direct spectrophotometry [1]. The main reagents are configured as follows:

A4-AAP solution: Weigh $2 \mathrm{~g}$ of 4-AAP dissolved in distilled water, and then dilute to $100 \mathrm{~mL}$ volumetric flask; B. Potassium ferricyanide solution: weigh $8 \mathrm{~g}$ of potassium ferricyanide dissolved in distilled water, and then make up to In a $100 \mathrm{~mL}$ volumetric flask; C. Buffer solution: $0.1 \mathrm{~mol} / \mathrm{L}$ ammonium chloride and $0.1 \mathrm{~mol} / \mathrm{L}$ ammonia water were mixed at a ratio of $2: 1$, and a buffer solution having a $\mathrm{pH}$ of 9.8 was measured by a $\mathrm{pH}$ meter.

(1) Phenol standard curve

First, draw a standard curve, take $850 \mathrm{~mL}$ colorimetric tubes, add $0,0.50,0.00,3.00,5.00,7.00,10.00,12.50 \mathrm{~mL}$ phenol standard intermediate solution, add ammonia-free water to $50 \mathrm{~mL}$ mark, add $0.5 \mathrm{~mL}$ buffer solution It was mixed and mixed with $1.0 \mathrm{~mL}$ of 4-AAP solution. Add $1.0 \mathrm{~mL}$ potassium ferricyanide solution, mix and place for $10 \mathrm{~min}$, immediately measure the absorbance at $510 \mathrm{~nm}$ wavelength with the optical path of $20 \mathrm{~nm}$ cuvette and water as reference. After blank correction, the absorbance is the standard curve of phenol content $(\mathrm{mg})$. The standard curve for phenol is shown in Figure 1.

(2) Determination of phenol water sample

The determination of the phenol water sample was similar to the standard curve drawing procedure, except that different volumes of phenol standard intermediate liquid were changed to $10 \mathrm{~mL}$ phenol water sample.

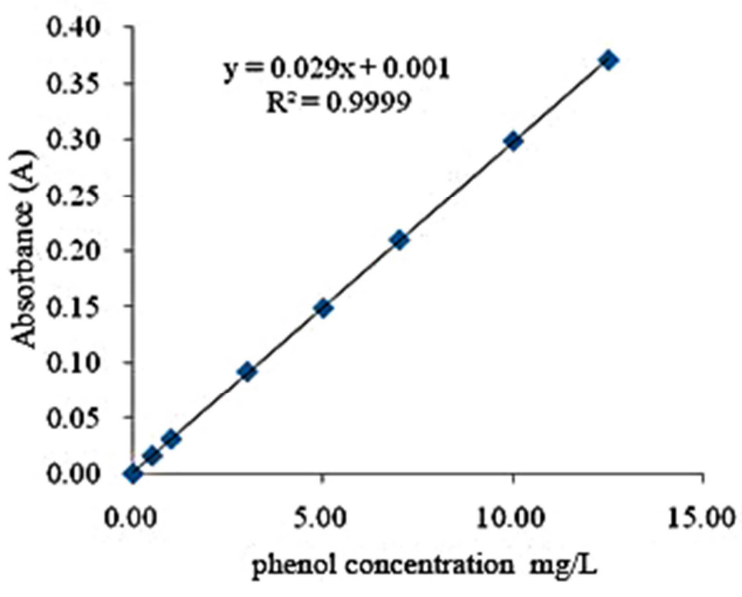

Figure 1. The standard curve of phenol.

As can be seen from Figure 1, the mass concentration is linear with the absorbance over a range of mass concentrations, which can be obtained by measuring the 
absorbance value and bringing it into a standard curve.

\subsubsection{Determination of COD}

Determination of chemical oxygen demand (COD) using rapid closed catalytic digestion. Calculated as follows

$$
\mathrm{CODcr}=\mathrm{C}\left(\mathrm{V}_{1}-\mathrm{V}_{2}\right) \times 8000 / \mathrm{V}_{0}
$$

Where $\mathrm{C}$ : the concentration of the standard titration solution of ammonium ferrous sulfate; $\mathrm{V}_{1}$ : the volume of the standard titration solution of ammonium ferrous sulfate consumed in the blank test; $\mathrm{V}_{2}$ : the sample is used to determine the volume of the standard titration solution of the ferrous ammonium sulfate consumed; 8000:1/4 $\mathrm{O}_{2}$ molar mass, $\mathrm{mg} / \mathrm{L}$ conversion value; $\mathrm{V}_{0}$ : volume of the sample.

\section{Experimental Study on Treating Phenol Wastewater}

The general oxidation of phenol by persulfate is that phenol is attacked by $\mathrm{SO}_{4}^{-}$. First, hydroquinone and catechol are formed, and then further oxidized to phenyl hydrazine, followed by ring opening to form a fatty carboxylic acid. It is oxidized to $\mathrm{CO}_{2}$ and $\mathrm{H}_{2} \mathrm{O}$ [3-4]. However, since both phenol and intermediate products are non-degradable organic substances, the color of the solution changes from colorless to brown when an intermediate reaction occurs, and deepens as the amount of the intermediate product increases.

Considering that the actual plant water containing various phenol industrial wastewaters is in a medium-high temperature $\left(20^{\circ} \mathrm{C} \sim 50^{\circ} \mathrm{C}\right)$ environment, based on the existing measurement data and test data, based on the standard, combined with the actual test conditions, set More objective and reasonable test parameters.

\subsection{Effect of Reaction Time}

$100 \mathrm{~mL}$ of phenol wastewater with an initial mass concentration of $200 \mathrm{mg} / \mathrm{L}$ and $0.05 \mathrm{~mol} / \mathrm{L} \mathrm{K}_{2} \mathrm{~S}_{2} \mathrm{O}_{8}$ standard solution was added to a $250 \mathrm{~mL}$ flask, and the $\mathrm{pH}$ of the water sample was adjusted to $\mathrm{pH}=3, \mathrm{~m}\left(\mathrm{~K}_{2} \mathrm{~S}_{2} \mathrm{O}_{8}\right)$ : $\mathrm{m}\left(\mathrm{C}_{6} \mathrm{H}_{6} \mathrm{O}\right)$ in a constant temperature water bath. The reaction was carried out at a constant temperature $\left(35^{\circ} \mathrm{C}\right)$ for 4 hours and sampled every 20 minutes. Three tests were carried out in parallel, and the supernatant was taken from a liquid surface of $1 \mathrm{~cm}$ to measure the COD value and the phenol value. The test results are shown in Figure 2.

It can be seen from the experimental observation that as time passes, the color of the solution gradually changes from colorless to brown, and deepens as the amount of the intermediate product increases. This is consistent with the phenol degradation law, but due to the lower removal rate, the solution is brown. shallow. It can be seen from Figure 2 that as the reaction time increases, the removal rate of phenol and COD increases gradually, and the removal rate of COD is always lower than the removal rate of phenol.

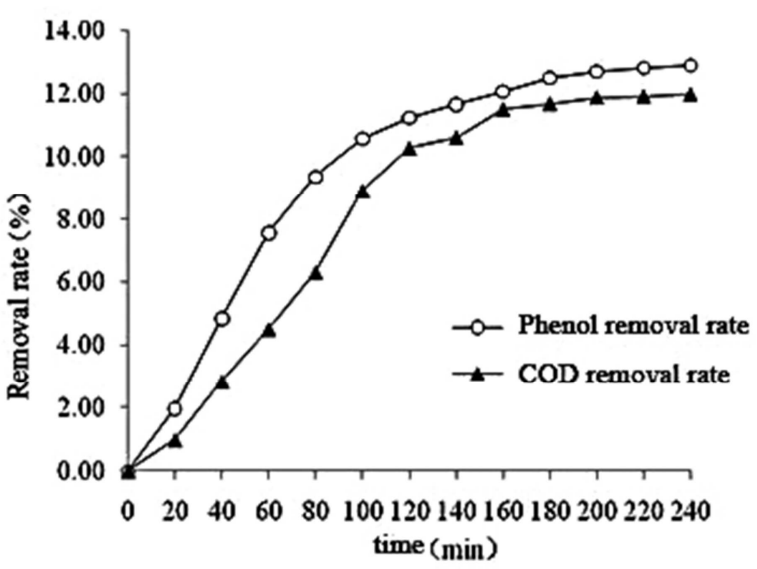

Figure 2. Influence of reaction time.

As can be seen from Figure 2, the removal rate of phenol is still relatively obvious as the reaction time is extended. The phenol and COD removal rates were only $4.86 \%$ and $2.83 \%$, respectively, during the first 40 minutes of the reaction. After $120 \mathrm{~min}$ of reaction, the removal rates of phenol and COD increased to $11.26 \%$ and $10.27 \%$, respectively, and then the upward trend was slow. When the reaction reached 180 minutes, the phenol removal rate reached $12.53 \%$ and the COD removal rate reached $11.68 \%$. The reaction then proceeds with time, but the oxidative degradation rate of phenol by $\mathrm{K}_{2} \mathrm{~S}_{2} \mathrm{O}_{8}$ gradually approaches zero, and the reaction enters a stage where oxidation is not easy. By the end of 240 minutes, the removal rates of phenol and COD reached $12.91 \%$ and $11.98 \%$, respectively. And the reaction time of $3 \mathrm{~h}$ is the experimental data of reasonable reaction time. When the reaction time is less than $3 \mathrm{~h}$, the degradation process of phenol is incomplete; after more than $3 \mathrm{~h}$, the removal rate of phenol and COD is slow, and the degradation rate is gradually close to zero. Considering economic factors, the time should not be too long, otherwise the operation cost will be greatly increased. Therefore, the test selected $3 \mathrm{~h}$ as a more suitable reaction time.

The phenol removal rate is always higher than COD throughout the reaction. The theoretical analysis is because the water sample is prepared by the laboratory itself. The production of COD is entirely from the phenol solution, and the degradation process of phenol is slow and complicated. The reaction is carried out in several stages and does not directly oxidize into small molecular inorganics. Therefore, the removal rates of phenol and COD are not the same, but the removal process and trend are more consistent. This analysis was mainly due to the 4-AAP direct spectrophotometric method for the determination of phenol content. In this process, when the para position is an alkyl group, the coupling of amino-antipyrine and phenol is more common in the para position. Substituent substitution, when the ortho position is unsubstituted, does not show a color reaction. Therefore, in this experimental study, the measured removal rate of volatile phenol was high, and the removal rate of COD did not exceed the removal rate of volatile phenol. 


\subsection{Effect of Potassium Persulfate Dosage}

$100 \mathrm{~mL}$ of phenol wastewater with an initial mass concentration of $200 \mathrm{mg} / \mathrm{L}$ and a $0.05 \mathrm{~mol} / \mathrm{L} \mathrm{K}_{2} \mathrm{~S}_{2} \mathrm{O}_{8}$ standard solution were added to a $250 \mathrm{~mL}$ flask to adjust the $\mathrm{pH}$ of the water sample to $\mathrm{pH}=3$, and the amount of $\mathrm{K}_{2} \mathrm{~S}_{2} \mathrm{O}_{8}$ was changed to carry out the reaction. The constant temperature water bath was kept at a constant temperature $\left(35^{\circ} \mathrm{C}\right)$ for 3 hours, so that $\mathrm{m}\left(\mathrm{K}_{2} \mathrm{~S}_{2} \mathrm{O}_{8}\right): \mathrm{m}\left(\mathrm{C}_{6} \mathrm{H}_{6} \mathrm{O}\right)=0.2$ to 2 , and a total of 10 water samples were taken. Three tests were performed in parallel, and the supernatant was taken from the liquid surface at $1 \mathrm{~cm}$ to measure the COD value and the phenol value. The test results are shown in Figure 3.

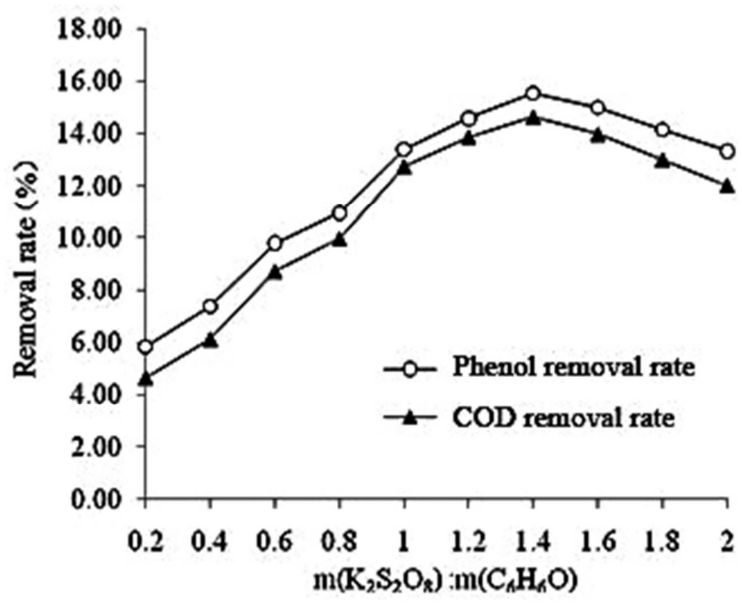

Figure 3. Effect of $\mathrm{K}_{2} \mathrm{~S}_{2} \mathrm{O}_{8}$ dosage.

It can be seen from the experimental observation that as the time increases, the color of the solution changes from colorless to brown, but due to the low removal rate, the solution is light brown, which is consistent with the phenol degradation law. As can be seen from Figure 3, the COD removal rate is always lower than the phenol removal rate. As the amount of $\mathrm{K}_{2} \mathrm{~S}_{2} \mathrm{O}_{8}$ increases, the removal rate of phenol and $\mathrm{COD}$ decreases. Upward trend. When $\mathrm{m}$ $\left(\mathrm{K}_{2} \mathrm{~S}_{2} \mathrm{O}_{8}\right): \mathrm{m}\left(\mathrm{C}_{6} \mathrm{H}_{6} \mathrm{O}\right)=0.2 \sim 0.6$, the removal rate of phenol is less than $9.78 \%$, and the removal rate of COD is less than $8.72 \%$. When $\mathrm{m}\left(\mathrm{K}_{2} \mathrm{~S}_{2} \mathrm{O}_{8}\right): \mathrm{m}\left(\mathrm{C}_{6} \mathrm{H}_{6} \mathrm{O}\right)=1$, the removal rate of phenol increased to $13.40 \%$, and the removal rate of COD increased to $12.75 \%$. After the addition of $\mathrm{K}_{2} \mathrm{~S}_{2} \mathrm{O}_{8}$, the removal rate of phenol and $\mathrm{COD}$ gradually decreased. When $\mathrm{m}\left(\mathrm{K}_{2} \mathrm{~S}_{2} \mathrm{O}_{8}\right): \mathrm{m}\left(\mathrm{C}_{6} \mathrm{H}_{6} \mathrm{O}\right)=1.4$, the removal rate of phenol and $\mathrm{COD}$ began to decrease, the amount of potassium persulfate continued to increase, and the degradation effect of phenol wastewater in the activation system became worse and worse. When $\mathrm{m}\left(\mathrm{K}_{2} \mathrm{~S}_{2} \mathrm{O}_{8}\right): \mathrm{m}\left(\mathrm{C}_{6} \mathrm{H}_{6} \mathrm{O}\right)=2$, the removal rates of phenol and COD were reduced to $13.31 \%$ and $12.03 \%$, respectively.

It can be seen from the experimental data that with the increase of the amount of $\mathrm{K}_{2} \mathrm{~S}_{2} \mathrm{O}_{8}$, the degradation rate of phenol increases correspondingly, and the removal rate of COD increases, but the removal effect of COD is not as good as that of phenol. When the amount of $\mathrm{K}_{2} \mathrm{~S}_{2} \mathrm{O}_{8}$ is small, the phenol rate is low and the degradation effect is not obvious.
When $\mathrm{m}\left(\mathrm{K}_{2} \mathrm{~S}_{2} \mathrm{O}_{8}\right): \mathrm{m}\left(\mathrm{C}_{6} \mathrm{H}_{6} \mathrm{O}\right)$ is more than 0.8, the removal effect is remarkably improved. This is because when $\mathrm{K} 2 \mathrm{~S} 2$ O 8 is added in a small amount, SO 4 - is small, and the degree of degradation of phenol is limited. When the content of $\mathrm{SO}_{4}^{-}$is increased to a certain extent, $\mathrm{K}_{2} \mathrm{~S}_{2} \mathrm{O}_{8}$ begins to exert its oxidizing ability, and the removal rate of phenol and COD is significantly increased. In addition, from the analysis and data in Figure 3, when the ratio of $\mathrm{K}_{2} \mathrm{~S}_{2} \mathrm{O}_{8}$ to phenol is greater than 1 and less than 1.4 , the degradation rate of phenol is slowed down, and the removal rate of phenol and COD is gradually increased. Close to stop. When the dose of $\mathrm{K}_{2} \mathrm{~S}_{2} \mathrm{O}_{8}$ continues to increase until the concentration exceeds a certain limit, it is uneconomical to waste the test agent. From the perspective of Figure 3, the removal rate of phenol and COD has decreased. The trend of this phenomenon is because when the concentration of $\mathrm{K}_{2} \mathrm{~S}_{2} \mathrm{O}_{8}$ in the solution is too high, too much $\mathrm{SO}_{4}{ }^{-}$will be produced, and excess $\mathrm{SO}_{4}{ }^{-}$ will combine with $\mathrm{S}_{2} \mathrm{O}_{8}{ }^{2-}$ to form $\mathrm{SO}_{4}{ }^{2-}$ and $\mathrm{S}_{2} \mathrm{O}_{8}{ }^{2-}$. Without oxidizing ability, the $\mathrm{SO}_{4}^{-}$- in the system is gradually reduced, and the quantity and concentration of effective molecules are reduced, thereby affecting the degradation of phenol wastewater. Therefore, this experiment uses $\mathrm{m}\left(\mathrm{K}_{2} \mathrm{~S}_{2} \mathrm{O}_{8}\right): \mathrm{m}\left(\mathrm{C}_{6} \mathrm{H}_{6} \mathrm{O}\right)=1$ as the best $\mathrm{K}_{2} \mathrm{~S}_{2} \mathrm{O}_{8}$ test, the dosage is more reasonable.

\subsection{Effect of $\mathrm{pH}$}

$100 \mathrm{~mL}$ of phenol wastewater with an initial mass concentration of $200 \mathrm{mg} / \mathrm{L}$ and $0.05 \mathrm{~mol} / \mathrm{L} \mathrm{K}_{2} \mathrm{~S}_{2} \mathrm{O}_{8}$ standard solution were added to a $250 \mathrm{~mL}$ flask. The dose was such that $\mathrm{m}\left(\mathrm{K}_{2} \mathrm{~S}_{2} \mathrm{O}_{8}\right): \mathrm{m}\left(\mathrm{C}_{6} \mathrm{H}_{6} \mathrm{O}\right)=1$, and the reaction was carried out in a constant temperature water bath at a constant temperature $\left(35^{\circ} \mathrm{C}\right)$ for 3 hours. Adjust the $\mathrm{pH}$ of the water sample to a $\mathrm{pH}$ of 1 to 13 , and take 13 water samples. Three tests were performed in parallel, and the supernatant was taken from the liquid surface at $1 \mathrm{~cm}$ to measure the COD value and the phenol value. The test results are shown in Figure 4.

It can be seen from the experimental observation that as time passes, the color of the solution gradually changes from colorless to brown, and deepens as the amount of the intermediate product increases, but the solution is light brown due to the lower removal rate, which is Phenol degradation is consistent. law. In addition, the degradation of phenol by $\mathrm{K}_{2} \mathrm{~S}_{2} \mathrm{O}_{8}$ is greatly affected by the $\mathrm{pH}$ change, and the color change is different due to the different $\mathrm{pH}$ values of the reaction.

As can be seen from Figure 4, the removal rate of phenol and $\mathrm{COD}$ varies with $\mathrm{pH}$, and the $\mathrm{COD}$ removal rate is always lower than the removal rate of phenol. When the $\mathrm{pH}$ is in the range of 1 to 3, the removal rate of phenol and COD increases with the increase of $\mathrm{pH}$. Under acidic conditions, phenol has a good removal effect on phenol. When the $\mathrm{pH}$ value is 3 , the optimum $\mathrm{pH}$ value of the reaction, the removal rate of phenol and COD reaches the maximum, $14.08 \%$ and $12.73 \%$, respectively. As the $\mathrm{pH}$ increases, the degradation effect decreases, and the removal rate of phenol and COD gradually decreases. Especially when the $\mathrm{pH}$ value is $7 \sim 8$, 
that is, the $\mathrm{pH}$ value is in the neutral range, the removal rate of phenol and COD is the smallest, and the degradation effect is the worst, indicating that $\mathrm{K}_{2} \mathrm{~S}_{2} \mathrm{O}_{8}$ is in a neutral environment. Basically, it is impossible to generate free radicals or ions having oxidizing power, and degradation of phenol wastewater tends to stagnate, reaching the most unfavorable reaction conditions.

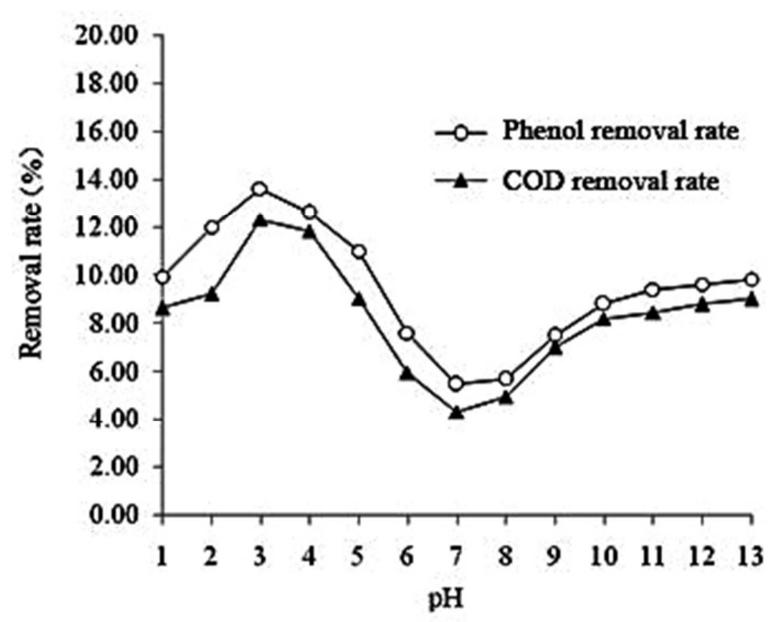

Figure 4. Effect of $P H$.

When the $\mathrm{pH}$ continues to rise and gradually changes to alkaline conditions, the ion activation effect of $\mathrm{K}_{2} \mathrm{~S}_{2} \mathrm{O}_{8}$ becomes better and the following reaction occurs due to the appearance of $\mathrm{OH}^{-}$:

$$
\mathrm{SO}_{4}^{-} \cdot+\mathrm{OH}^{-} \rightarrow \cdot \mathrm{OH}+\mathrm{SO}_{4}{ }^{2-}
$$

W When $\cdot \mathrm{OH}$ appears and accumulates to a certain amount, it will replace $\mathrm{SO}_{4}{ }^{-}$to exert the strong oxidizing ability to treat pollutants. This reaction rule can also be seen from Figure 4. After the $\mathrm{pH}$ is greater than 9, the removal rate of phenol and COD is obviously increased. When $\mathrm{pH}=13$, the removal rates of phenol and COD have risen to $9.81 \%$ and $9.00 \%$, respectively. In general, the degradation effect of phenol solution is greatly affected by $\mathrm{pH}$ value. In practical applications, it is necessary to fully consider the control and grasp of $\mathrm{pH}$ to ensure the treatment effect of $\mathrm{K}_{2} \mathrm{~S}_{2} \mathrm{O}_{8}$ on phenol wastewater.

\subsection{Effect of Initial Phenol Concentration}

Add $100 \mathrm{~mL}$ of different initial concentrations of phenol wastewater to a $250 \mathrm{~mL}$ flask, take 8 samples in the concentration range of $50 \mathrm{mg} / \mathrm{L}$ to $300 \mathrm{mg} / \mathrm{L}$, and add 0.05 $\mathrm{mol} / \mathrm{L} \quad \mathrm{K}_{2} \mathrm{~S}_{2} \mathrm{O}_{8}$ standard solution to make $\mathrm{m}\left(\mathrm{K}_{2} \mathrm{~S}_{2} \mathrm{O}_{8}\right): \mathrm{m}\left(\mathrm{C}_{6} \mathrm{H}_{6} \mathrm{O}\right)=1$, adjust the $\mathrm{pH}$ of the water sample to make $\mathrm{pH}=3$. The reaction was carried out in a constant temperature water bath at a constant temperature $\left(35^{\circ} \mathrm{C}\right)$ for $3 \mathrm{~h}$, and the test was carried out 3 times in parallel, and the supernatant was taken at a distance of $1 \mathrm{~cm}$ from the liquid surface, and the COD value and the phenol value were respectively measured. The test results are shown in Figure 5.

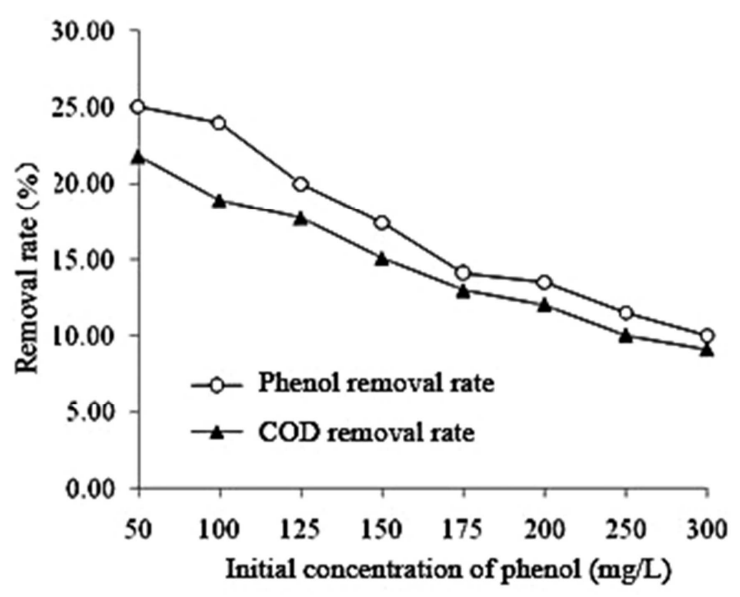

Figure 5. Influence of initial phenol concentration.

It can be seen from the experimental observation that since the water samples in the group are divided into different concentration values, the color change of the solution is slightly different. When the initial concentration of phenol is less than $100 \mathrm{mg} / \mathrm{L}$, the color of the whole degradation process is basically unchanged due to the small concentration; when the initial concentration of phenol is more than $200 \mathrm{mg} / \mathrm{L}$, the color of the solution gradually changes from colorless to brown during the reaction. It is brown and deepens because of the increase in the amount of intermediate product, but the solution is lighter brown due to the lower removal rate. It can be seen from Figure 5 that with the increase of the initial concentration of phenol, the removal rate of phenol and COD decreases gradually, and the COD removal rate is always lower than the removal rate of phenol. When the initial concentration of phenol was at least $50 \mathrm{mg} / \mathrm{L}$, the removal rates of phenol and COD were the highest, $25.02 \%$ and $21.81 \%$, respectively. After that, the phenol removal rate decreased to $10.07 \%$ and the COD removal rate was only $9.03 \%$ when the initial concentration of phenol increased to $300 \mathrm{mg} / \mathrm{L}$. This is because when the initial concentration of the pollutant is too high, the amount of $\mathrm{SO}_{4}^{-} \cdot$ produced by potassium persulfate is small, the amount of oxidation cannot satisfy the consumption of the pollutant, and the degradation is not thorough enough to affect the degradation effect of the phenol wastewater.

From the overall test, the degradation efficiency of phenol wastewater decreases with increasing concentration, which is related to the amount of free radicals and ions that can participate in the solution, but the reduction of degradation efficiency does not show a significant linear change with the decrease of concentration. Instead, it presents an irregular downward trend. By comparing the specific data of the test, when the initial concentration of phenol is $200 \mathrm{mg} / \mathrm{L}$, the phenol removal rate is $13.51 \%$, the COD removal rate is $12.07 \%$, and the normal removal rate of the phenol wastewater treated by the heat activated potassium persulfate at $35^{\circ} \mathrm{C}$. Moreover, when the initial concentration of phenol is less than $200 \mathrm{mg} / \mathrm{L}$, the rate of decline of phenol removal rate changes with the decrease of concentration, while at the initial concentration of phenol is more than $200 \mathrm{mg} / \mathrm{L}$, the 
decline rate of phenol removal rate gradually decreases. Therefore, in this test, $200 \mathrm{mg} / \mathrm{L}$ was selected as the initial concentration of phenol which is suitable under the reaction conditions.

\subsection{Effect of Reaction Temperature}

$100 \mathrm{~mL}$ of $200 \mathrm{mg} / \mathrm{L}$ phenol wastewater and $0.05 \mathrm{~mol} / \mathrm{L}$ $\mathrm{K}_{2} \mathrm{~S}_{2} \mathrm{O}_{8}$ standard solution were added to a $250 \mathrm{~mL}$ flask to make $\mathrm{m}\left(\mathrm{K}_{2} \mathrm{~S}_{2} \mathrm{O}_{8}\right): \mathrm{m}\left(\mathrm{C}_{6} \mathrm{H}_{6} \mathrm{O}\right)=1$, and the $\mathrm{pH}$ of the water sample was adjusted to $\mathrm{pH}=3$. The reaction was carried out for 3 hours in a constant temperature water bath, and different temperature values were adjusted. A total of 11 temperature zones were set between $20^{\circ} \mathrm{C}$ and $99.5^{\circ} \mathrm{C}$. The parallel test was carried out 3 times, and the supernatant was taken $1 \mathrm{~cm}$ from the liquid surface to measure the COD value and phenol. Value, the test results are shown in Figure 6.

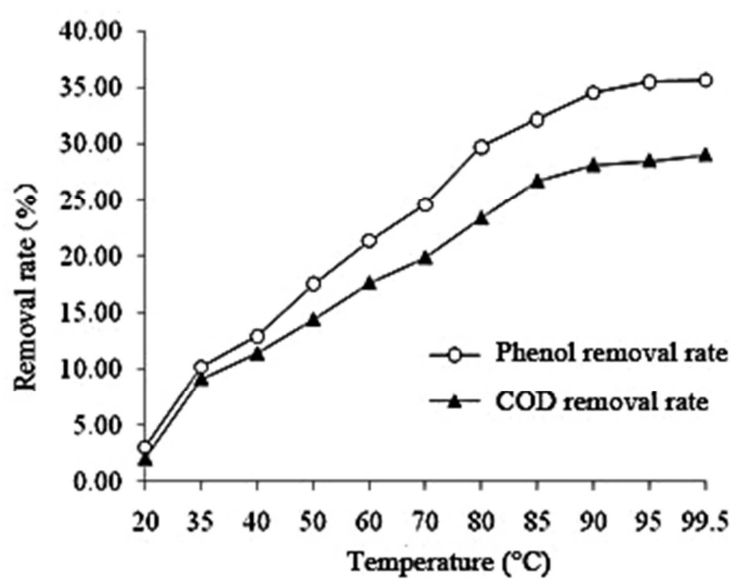

Figure 6. Effect of reaction temperature.

It can be seen from the experimental observation that the color of the solution gradually changes from colorless to brown in the course of the reaction and the temperature gradually increases, and deepens as the amount of the intermediate product increases. It can be seen from Figure 6 that as the reaction temperature increases, the removal rate of phenol and COD gradually increases, and the COD removal rate is always lower than the removal rate of phenol. When the temperature is lower than $20^{\circ} \mathrm{C}$, the phenol is not degraded, the removal rate of phenol and COD is only $3.08 \%$ and $2.01 \%$; when the temperature is between $35^{\circ} \mathrm{C}$ and $80^{\circ} \mathrm{C}$, the degradation effect is obviously enhanced with the increase of temperature; when the temperature is greater than At $85^{\circ} \mathrm{C}$, the removal rate of phenol and COD increased slowly. When the temperature is raised to $99.5^{\circ} \mathrm{C}$, the degradation rate of phenol wastewater increases to near zero. At this time, the maximum removal rate of phenol is $35.63 \%$, and the maximum removal rate of COD is $29.06 \%$. From the results of Figure 6 and test data, when the temperature is increased to $85^{\circ} \mathrm{C}, \mathrm{K}_{2} \mathrm{~S}_{2} \mathrm{O}_{8}$ has been fully activated, and its good oxidation capacity is exerted. The treatment effect of phenol wastewater is good, and the removal rates of phenol and COD are $32.17 \%$. And $26.72 \%$. Therefore, $85^{\circ} \mathrm{C}$ is set as a reasonable high temperature heating temperature under the premise of ensuring the treatment effect and avoiding unnecessary energy waste.

It is seen from the test results that the temperature has a significant effect on the treatment of the phenol solution with potassium persulfate. This is because heating has a significant activation effect on potassium persulfate. That is the heating condition provides enough energy for the reaction system to force the bis-oxygen bond to break [5-6], so that the sulfate radical is released and the oxidizing ability is enhanced, so that the degree of oxidation of phenol is deepened, and finally phenol and COD are obtained. The result of increased removal rate. It can be seen that heating is a simple and effective persulfate activation method, and the effect of temperature on the treatment of phenol solution with potassium persulfate cannot be ignored.

\subsection{Effect of Reaction Temperature}

Add The principle of heat activated $\mathrm{K}_{2} \mathrm{~S}_{2} \mathrm{O}_{8}$ system for treating pollutants is that $\mathrm{S}_{2} \mathrm{O}_{8}{ }^{2-}$ is generated under heating conditions. Produced $\mathrm{SO}_{4}^{-} \cdot$ reacts with $\mathrm{OH}^{-}$after dissociation from water or water molecules to form $\mathrm{OH}$ [7-8]. The basic reaction of this principle is as follows:

$$
\begin{gathered}
\mathrm{S}_{2} \mathrm{O}_{8}{ }^{2-} \text { heat } \rightarrow 2 \mathrm{SO}_{4}{ }^{-} . \\
\mathrm{SO}_{4}{ }^{-} \cdot+\mathrm{OH}^{-} \rightarrow \cdot \mathrm{OH}+\mathrm{SO}_{4}{ }^{2-}
\end{gathered}
$$

The simultaneous presence of $\mathrm{SO}_{4}{ }^{-} \cdot \sqrt{\cdot} \mathrm{OH}$ in the reaction process is prominent in the study of the $\mathrm{pH}$ value of the activated $\mathrm{K}_{2} \mathrm{~S}_{2} \mathrm{O}_{8}$ treated phenol wastewater. $\mathrm{SO}_{4}{ }^{-} \cdot$ and $\cdot \mathrm{OH}$ are strong oxidizing substances that can degrade organic pollutants. In order to prove the different effects of the two in the activation of $\mathrm{K}_{2} \mathrm{~S}_{2} \mathrm{O}_{8}$ treated phenol wastewater, the test used the difference in the reaction rate of the radical with t-butanol and methanol to determine the type of radical [1-2] in the system of heat-activated $\mathrm{K}_{2} \mathrm{~S}_{2} \mathrm{O}_{8}$.

The test method is feasible because the reaction rate constant of tert-butanol and $\cdot \mathrm{OH}$ is $3.8 \times 10^{8} \sim 7.6 \times 10^{8} \mathrm{~L} / \mathrm{mol} / \mathrm{s}$, and the reaction rate with $\mathrm{SO}_{4}{ }^{-} \cdot$ is $4.0 \times 10^{5} \sim 9.1 \times 10^{5} \mathrm{~L} / \mathrm{mol}$ $/ \mathrm{s}$, that is, the reaction rate of t-butanol and $\cdot \mathrm{OH}$ is almost 1000 times the reaction rate of $\mathrm{SO}_{4}{ }^{-\cdots}$ The reaction rate of methanol and the two is relatively close. The reaction rate constant of methanol and $\cdot \mathrm{OH}$ is $1.2 \times 10^{9} \sim 2.8 \times 10^{9} \mathrm{~L} / \mathrm{mol} / \mathrm{s}$, and the reaction rate constant with $\mathrm{SO}_{4}^{-} \cdot$ It is $1.6 \times 10^{7} \sim$ $7.7 \times 10^{7} \mathrm{~L} / \mathrm{mol} / \mathrm{s}$ [9-10]. Therefore, by comparing the change of phenol removal rate before and after the addition of excess t-butanol, it can be judged whether or not $\cdot \mathrm{OH}$ exists in the heat activated $\mathrm{K}_{2} \mathrm{~S}_{2} \mathrm{O}_{8}$ system; then excess methanol is added to the system, and the comparison of the butanol system can eliminate the influence of $\cdot \mathrm{OH}$ and determine whether $\mathrm{SO}_{4}{ }^{-} \cdot$ is formed in the system. In order to fully highlight the test results of this test, combined with the previous test results, the more suitable reaction conditions are selected, and the specific test methods are as follows.

In a $250 \mathrm{~mL}$ flask, $100 \mathrm{~mL}$ of phenol with an initial mass concentration of $200 \mathrm{mg} / \mathrm{L}$ and a $\mathrm{K}_{2} \mathrm{~S}_{2} \mathrm{O}_{8}$ standard solution of $0.05 \mathrm{~mol} / \mathrm{L}$ were added, and the dosage of $\mathrm{K}_{2} \mathrm{~S}_{2} \mathrm{O}_{8}$ was set such 
that $\mathrm{m}\left(\mathrm{K}_{2} \mathrm{~S}_{2} \mathrm{O}_{8}\right): \mathrm{m}\left(\mathrm{C}_{6} \mathrm{H}_{6} \mathrm{O}\right)=1$, and the $\mathrm{pH}$ of the water sample was adjusted. $\mathrm{pH}=3$, reacted in a constant temperature water bath at a constant temperature $\left(85^{\circ} \mathrm{C}\right)$ for $3 \mathrm{~h}$, parallel test 3 times, take the supernatant from the liquid surface $1 \mathrm{~cm}$, and measure the COD value and the phenol value respectively. The test results are shown in Figure 7.

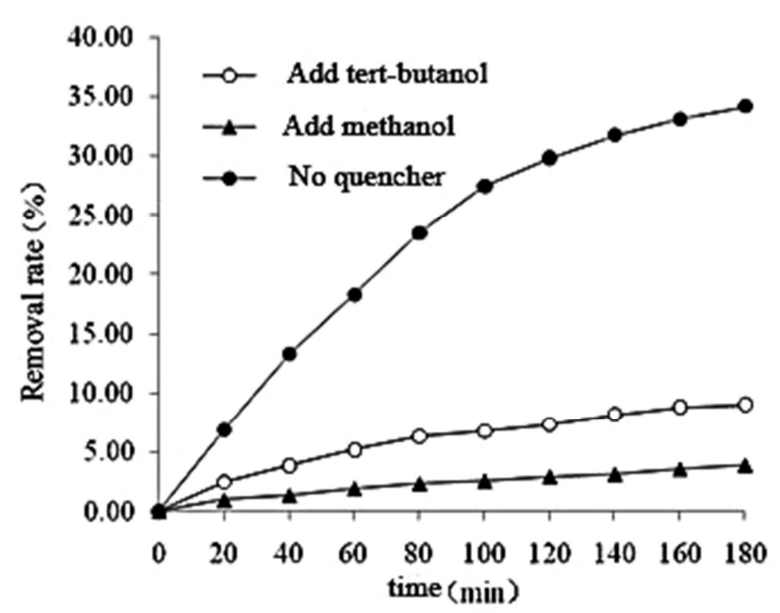

Figure 7. Effect of Quencher on Thermally Activated $\mathrm{K}_{2} \mathrm{~S}_{2} \mathrm{O}_{8}$ System.

As shown in Figure 7, when the alcohol quencher was added to the heat activated $\mathrm{K}_{2} \mathrm{~S}_{2} \mathrm{O}_{8}$ system, the degradation of phenol wastewater was strongly inhibited, and the inhibition effect of methanol was much more serious than that of t-butanol. This phenomenon is evident from the beginning of the reaction. When the reaction was just carried out for $20 \mathrm{~min}$, the phenol removal rate had reached $6.90 \%$ in the thermally activated $\mathrm{K}_{2} \mathrm{~S}_{2} \mathrm{O}_{8}$ system without quenching agent. In the system with t-butanol added, the phenol removal rate was only $2.49 \%$; in the methanol-added system, the phenol removal rate was lower, only $0.98 \%$, and the phenol wastewater was not substantially degraded.

With the extension of time, the reaction proceeded smoothly in the heat-activated $\mathrm{K}_{2} \mathrm{~S}_{2} \mathrm{O}_{8}$ system without quenching agent, and the phenol removal rate was further improved rapidly. The two groups of experiments with the addition of alcohol quenchers continued to progress slowly. When the reaction proceeded to $140 \mathrm{~min}$, the phenol removal rate easily increased to $31.70 \%$ without the addition of a quencher to the thermally activated $\mathrm{K}_{2} \mathrm{~S}_{2} \mathrm{O}_{8}$ system. In the system with tert-butanol, the phenol removal rate reached $8.19 \%$; in the methanol-added system, the phenol removal rate was still only at least $3.15 \%$, and the phenol wastewater treatment effect was not satisfactory. When the test was finished, the heat-activated $\mathrm{K}_{2} \mathrm{~S}_{2} \mathrm{O}_{8}$ system without quencher was used, and the phenol removal rate reached $34.13 \%$. In the system with tert-butanol added, the phenol removal rate reached $9.03 \%$; in the methanol-added system, the phenol removal rate only increased to $3.91 \%$.

From the test results, it is known that the addition of tert-butanol and methanol in the heat activated $\mathrm{K}_{2} \mathrm{~S}_{2} \mathrm{O}_{8}$ system, the degradation process of phenol is significantly inhibited, the system of adding tert-butanol, the removal rate of phenol is less than $1 / 3$ of the quenching agent. It indicates that $\cdot \mathrm{OH}$ exists in the system, and $\mathrm{OH}$ plays a certain role in the oxidation process. The inhibitory effect of the heat-activated $\mathrm{K}_{2} \mathrm{~S}_{2} \mathrm{O}_{8}$ system with methanol addition was more significant, and its inhibition was much more pronounced than that of the system with t-butanol. After the addition of methanol, the phenol removal rate was less than $1 / 10$ of that of the unquenched agent, and the degradation process of the phenol wastewater was almost completely inhibited. This indicates that $\mathrm{SO}_{4}^{-} \cdot$ exists in the degradation of phenol wastewater, and $\mathrm{SO}_{4}{ }^{-}$. plays a leading role in the process of oxidizing pollutants, and $\cdot \mathrm{OH}$ plays a supporting role. Since the test method of this test is universal, the test results are applicable to other activation systems.

\section{Conclusion}

This chapter studies the experimental results of heat activated potassium persulfate treatment of phenol wastewater. Through the analysis of the test data, the following conclusions are drawn:

(1) In the experimental study of heating activated potassium persulfate to treat phenol wastewater, the treatment of phenol wastewater was not satisfactory due to temperature limitation, and the removal rates of phenol and COD were only about $12 \%$ and $11 \%$, respectively. In the experimental study, it was found that the reaction time, the dosage of $\mathrm{K}_{2} \mathrm{~S}_{2} \mathrm{O}_{8}$, the $\mathrm{pH}$ value of phenol wastewater, the initial concentration of phenol and the reaction temperature had an effect for the treatment of phenol wastewater. Under the condition of heating and activation at $35^{\circ} \mathrm{C}$, when the initial concentration of phenol is $200 \mathrm{mg} / \mathrm{L}$, the reaction time is $180 \mathrm{~min}$, the $\mathrm{pH}$ value is $3.0, \mathrm{~m}\left(\mathrm{~K}_{2} \mathrm{~S}_{2} \mathrm{O}_{8}\right): \mathrm{m}\left(\mathrm{C}_{6} \mathrm{H}_{6} \mathrm{O}\right)=1$, and the optimal removal rate of phenol is $13.61 \%$, COD. The optimum removal rate was $12.30 \%$. It is worth noting that the test results of changing the $\mathrm{pH}$ value of the test and the treatment of phenol wastewater by heat-activated $\mathrm{K}_{2} \mathrm{~S}_{2} \mathrm{O}_{8}$ are divided into three different situations: acidic, neutral and alkaline. In addition, the heating temperature has a great influence on the treatment of phenol wastewater by $\mathrm{K}_{2} \mathrm{~S}_{2} \mathrm{O}_{8}$. When the temperature is increased to $85^{\circ} \mathrm{C}$ under the same reaction conditions, the removal rates of phenol and COD increase to $32.17 \%$ and $26.72 \%$, respectively.

(2) In the experimental study, it was found that the heat activated $\mathrm{K}_{2} \mathrm{~S}_{2} \mathrm{O}_{8}$ system without quenching agent can degrade phenol wastewater normally. After the addition of the alcohol quencher, the removal rate of phenol decreased significantly, and the inhibition of methanol was significantly stronger than that of tert-butanol. This indicates that $\mathrm{SO}_{4}^{-} \cdot$ and $\cdot \mathrm{OH}$ coexist in the degradation process of phenol wastewater, and in the process of oxidizing pollutants, $\mathrm{SO}_{4}{ }^{-}$plays a leading role, and $\cdot \mathrm{OH}$ plays a supporting role.

\section{Acknowledgements}

This research was supported by the Natural Science Foundation of China (grant number Z1115073). 


\section{References}

[1] Wu Chengqiang, Zuo Xiaomei, Fu Danting. US-UV-Fenton degradation of nitrobenzene [J]. Journal of Environmental Engineering, 2014, 8 (12), pp. 5073-5078.

[2] Yang Tao, Lin Fengkai, Ma Hainan, et al. UV-ultrasonic coupling degradation of phenol and chlorobenzene in aqueous solution [J]. Modernization, 2014, 34 (11), pp. 87-91.

[3] Zhu Jie, Luo Qishi, Guo Lin, Liu Xiaoning, et al. Experimental study on oxidation of chlorobenzene in water by alkaline heat activated persulfate $[\mathrm{J}]$. Environmental Chemistry, 2013, 32 (12), pp. 256-2262.

[4] Fan Congjian, Liu Shijun, Liu Zhe, Cui Yuhong, et al. Research progress in the removal of organic pollutants in water by persulfate technology [J]. Environmental Science and Technology, 2015, S1, pp. 136-141.

[5] C Tan, N Gao, Y Deng, L Li, etc. Kinetic oxidation of antipyrine in heat-activated persulfate $[\mathrm{J}]$. Desalination \& Water Treatment, 2013, 53 (1), pp. 263-271.

[6] N Gao, Y Deng, N An, etc. Heat-activated persulfate oxidation of diuron in water [J]. Desalination \& Water Treatment, 2014, 203, pp. 294-300.

[7] Yang Shiying, Yang Xin, Wang Ping, Shan Liang, Zhang Wenyi. Research progress on activation methods of persulfate advanced oxidation technology [J]. Modern Chemical Industry, 2009, 29 (4), pp. 13-19.

[8] Lin Ya-Ting, Liang Chenju, Chen, etc. Feasibility study of ultraviolet activated persulfate oxidation of phenol [J]. Chmosphere, 2011 (8), pp. 1168-1172.

[9] Zhang Zhonglei, Chen Hai, Yang Qi, Li Bo. FeS/ $\mathrm{K}_{2} \mathrm{~S}_{2} \mathrm{O}_{8}$ removes 2,4-D from water systems [J]. Journal of Environmental Engineering, 2014, 8 (11), pp. 4631-4635.

[10] Xu Xiwei, Zeng Zhuo. Study on the catalytic oxidation of hydroquinone by activated carbon by potassium persulfate $[\mathrm{J}]$. Journal of Central South University of Forestry and Technology, 2012, 32 (8): 117-121.

[11] Ma Nan, Tian Yaojin, Yang Guangping, Xie Xinyuan. Study on the degradation of phenol wastewater by modified activated carbon fiber and electric Fenton [J]. Chinese Journal of Environmental Science, 2014, 35 (7), pp. 2627-2638.

[12] Wang Zheming, Wang Jinming, Ruan Chuanli, et al. Research progress of microwave induced catalytic oxidation wastewater treatment [J]. Water Treatment Technology, 2010, 36 (7), pp. $24-28$

[13] Liu Guifang, Sun Yaquan, Lu Hongyu, et al. Research progress in activated persulfate technology [J]. Industrial Water Treatment, 2012, 32 (12): 6-10.

[14] YC Lee, SL Lo, PT Chiueh, etc. Microwave-hydrothermal Decomposition of the Perfluorooctanoic Acid in Water by Iron Activated Persulfate Oxidation [J]. Water Research, 2010, 44 (3): 886-892.

[15] N Gao, Y Deng, N An, J Deng, C Tan. Heat-activated persulfate oxidation of diuron in water [J]. Desalination \& Water Treatment, 2014, 203: 294-300.

[16] Liu Guoqiang, Wang Binnan, Liao Yunyan, et al. Thermally activated persulfate degradation of 2-chlorobenzene in water [J]. Environmental Chemistry, 2014, 33 (8): 1396-1403. 